\title{
Relationship between extractable chlorophyll content and SPAD values in three varieties of Kacip Fatimah under greenhouse conditions
}

\begin{abstract}
Relationship between extractable chlorophyll and relative chlorophyll values obtained using Soil Plant Analytical Development (SPAD)-502 meter were determined in three varieties of Labisia pumila (alata, pumila, lanceolata) under greenhouse conditions using fresh weight basis. The experiment was arranged as a complete randomized design replicated three times with each experimental unit containing five plants. There were no significant differences $(\mathrm{P} \geq$ 0.05) for all the three varieties in their chlorophyll $a, b$ and total. Best fit relationship was found to be linear in chlorophyll $\mathrm{a}, \mathrm{b}$ and total $(\mathrm{P} \leq 0.01)$ with ascending slope as SPAD values intensified. Chlorophyll $\mathrm{b}$ was higher than chlorophyll $\mathrm{a}$ in all the varieties indicating species as shade-loving plants. The chlorophyll content of $\mathrm{L}$. pumila leaves can be conveniently determined using SPAD-502 chlorophyll meter, a technique providing simple, rapid, and nondestructive method to estimate leaf chlorophyll content which could also be an indicator of leaf nitrogen $(\mathrm{N})$ status.
\end{abstract}

Keyword: Chlorophyll a and b; Indirect plant nutrient status; Nondestructive chlorophyll estimation; Shade loving species 